\title{
Simulation of Heat-Transfer Processes and Assessment of the Viscoplastic Parameters of Iron Ore in Blast Furnaces
}

\author{
V. V. Lavrov ${ }^{a}$, N. A. Spirin ${ }^{a}$, A. A. Burykin ${ }^{a}$, O. P. Onorin ${ }^{b}$, I. E. Kosachenko \\ A. V. Krasnobaev ${ }^{c}$, and V. Yu. Rybolovlev ${ }^{c}$ \\ ${ }^{a}$ Yeltsin Ural Federal University \\ ${ }^{b} \mathrm{OAO}$ Ural'skii Institut Metallov \\ ${ }^{c}$ OAO Magnitogorskii Metallurgicheskii Kombinat (MMK) \\ Received January 22, 2013
}

\begin{abstract}
Stages in the development of an information and simulation system for assessing the position and shape of the viscoplastic iron-ore zone (the cohesion zone) in the blast furnace are outlined. This system also permits diagnostics of the zone's optimal configuration on the basis of available operational information for the furnace in the baseline period. In addition, the system proves useful during the design period, with variation in the smelting parameters. The capabilities of the corresponding software are discussed, and its use in blast-furnace control at OAO Magnitogorskii Metallurgicheskii Kombinat is demonstrated.
\end{abstract}

DOI: $10.3103 / \mathrm{S} 0967091213040086$

Large Russian metallurgical enterprises are increasingly using algorithms and software as part of manufacturing execution systems (MES). This calls for the development of specialized information and simulation software that takes account of the physics of metallurgical processes, the principles of mass- and heat-transfer theory, and the law of energy conservation and also of the influence of the raw materials on the process [1, 2]. Integration of this software with existing corporate systems and production systems is of the greatest importance.

Blast-furnace performance is largely determined by the viscoplastic state of the iron ore. The shape and position of the plastic zone within the blast furnace depends on factors such as the ore distribution over the furnace cross section and the viscoplastic characteristics of the iron ore: the initial viscoplastic temperature and the melting point (the temperature at which slag melt appears). The productivity is greatest with the best shape and smallest thickness of the plastic zone and also with good melt filtration into the zone below the plastic zone $[3,4]$.

Despite new means of determining the position of the plastic zone in the blast furnace-including mathematical simulation [5-12] - it is important to create ongoing monitoring and analysis of its position in the course of smelting.

The familiar principle of perturbed-unperturbed motion is used in developing a mathematical model for the information and simulation system used in calculating the heat-transfer processes and assessing the parameters of the viscoplastic zone in the iron ore [13]. We may divide the model of the blast-furnace process into two parts: the model of the baseline state and a predictive model. The model of the baseline state permits assessment of the state of the process by means of mean characteristics for the baseline period of furnace operation. The predictive model employs the results from the model of the baseline state to assess the blast-furnace characteristics with change in the smelting conditions. This principle was successfully used earlier in simulating the thermal, blast, gasdynamic, and slag conditions of smelting [1,2].

Since the mathematical model of the position and configuration of the viscoplastic zone in the iron ore is too complex to permit easy derivation of a subsystem in software form, we must resort to functional modeling, with detailed development of the specifications for the individual model components [14].

Functional modeling is based on the IDEF0 standard (Integrated computer-aided manufacturing Definition), which is a development of the SADT method (Structural Analysis and Design Technique) [14]. The IDEF0 procedure permits the creation of a functional structure for the information and simulation system, the identification of productive actions and the relation between those actions, and the mechanisms by which each function is performed. This approach permits the prevention of possible errors at an early stage of design. For this purpose, we use a CASE system: the AllFusion Process Modeler (BPwin) [15].

In all, there are 104 component modules of the functional model. A fragment of the first level of the functional model corresponding to simulation of the viscoplastic zone in the iron ore is shown in Fig. 1. Its functions are as follows. 


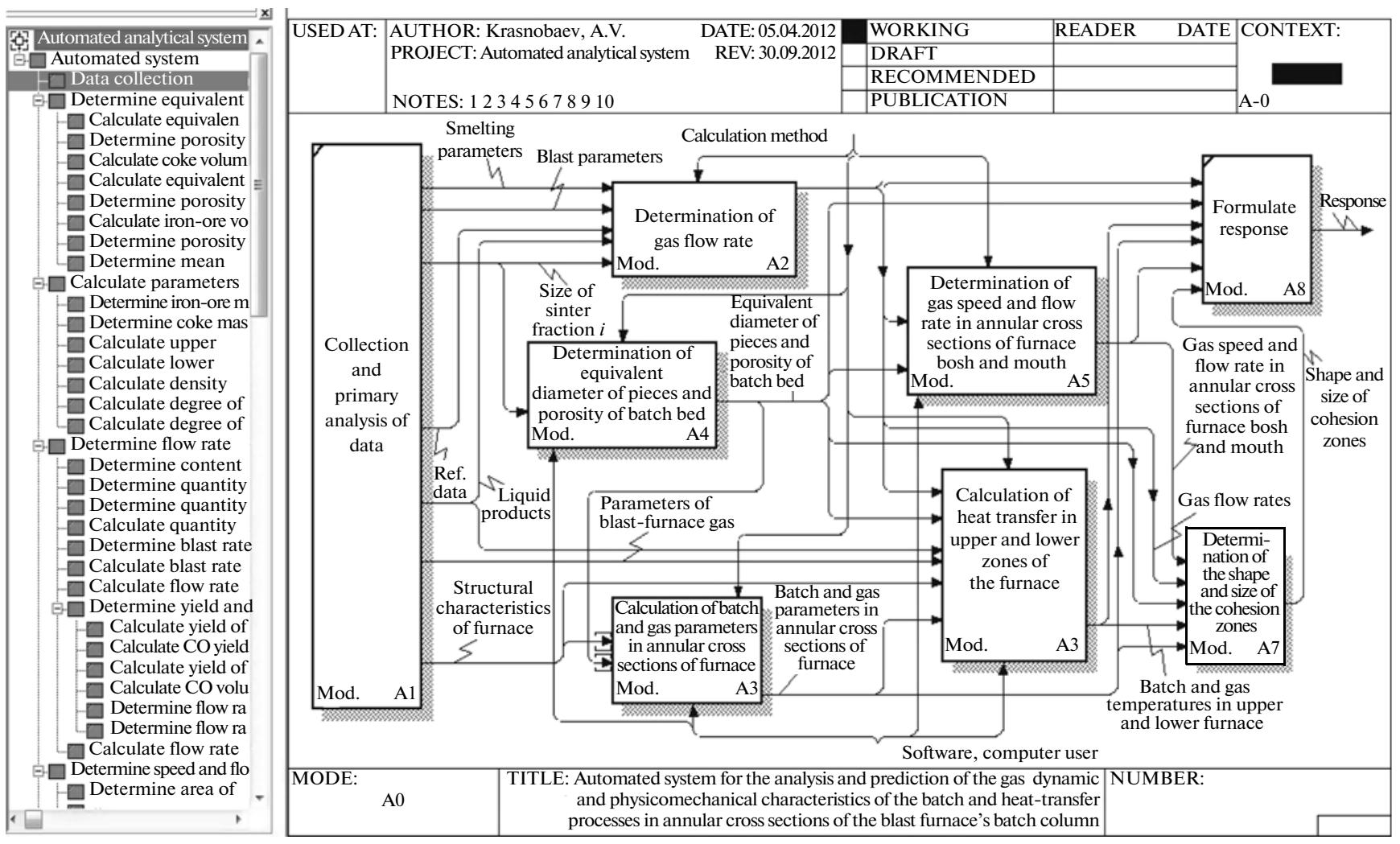

Fig. 1. Fragment of the functional model corresponding to simulation of the viscoplastic zone in iron ore.

Module A1: selection and primary analysis of the data. This module ensures automatic processing of data from the overall control system and the monitoring systems. The primary data are collected at strictly specified times corresponding to the requirements of the engineering staff in the blast-furnace shop. The output information from this module is provided to all the other subsystems.

Module A2: determining the equivalent diameters of the pieces and the porosity of the batch bed. This module ensures calculation of the equivalent diameters of the coke and sinter pieces and the porosity of the layers of coke, sinter, and pellets.

Module A3: calculating the batch and gas parameters in annular furnace cross sections. This module ensures calculation of the coke and iron-ore mass per $1 \mathrm{~m}^{3}$ of batch in annular cross sections; the density of the batch and the iron ore and the degree of equilibrium of the batch in each annular cross section in the upper and lower furnace zones; and the upper and lower pressure differences of the gas.

Module A4: Determining the gas flow rate. This module ensures calculation of the content of nonvolatile carbon in the coke; the quantity of carbon in the coke supplied to the furnace; the quantity of carbon in the coke that is consumed in the direct reduction of iron oxides and impurities of the hot metal; the quantity of carbon in the coke that burns up at the tuyeres; the consumption of natural gas per $1 \mathrm{~kg}$ of carbon in the coke burning at the tuyeres; blast fuel required for combustion of $1 \mathrm{~kg}$ of coke from the tuyeres; the blast flow rate required for the conversion of $1 \mathrm{~m}^{3}$ of natural gas; the specific blast flow rate; the yield of hearth gas in the combustion of $1 \mathrm{~kg}$ of carbon from the coke at the air tuyeres; the yield of hearth gas in the conversion of $1 \mathrm{~m}^{3}$ of natural gas at the air tuyeres; the specific yield of hearth gas; the $\mathrm{CO}$ yield in the direct reduction of iron oxides and impurities of the hot metal; the volume of $\mathrm{CO}_{2}$ obtained in the decomposition of limestone; and the yield of blast-furnace gas.

Module A5: determining the gas speed and flow rate in the annular cross sections of the furnace's bosh and mouth. This module calculates characteristics such as the volume of coke and iron ore in the annular cross sections; the porosity of the batch bed in each annular cross section of the cohesion zone and the melt-filtration zone; the gas velocity in the calculated bosh cross section the bulk flow rate of gas in the annular cross sections of the bosh; the bulk gas flow rate in the annular cross sections of the bosh; the bulk flow rate of gas passing through the calculated annular cross sections to the furnace mouth; the yield of hearth gas; and the mean filtration rate of the gas in the bosh.

Module A6: calculation of the heat transfer in upper and lower zones of the furnace. This module calculates the specific-heat ratio of the batch and gas 


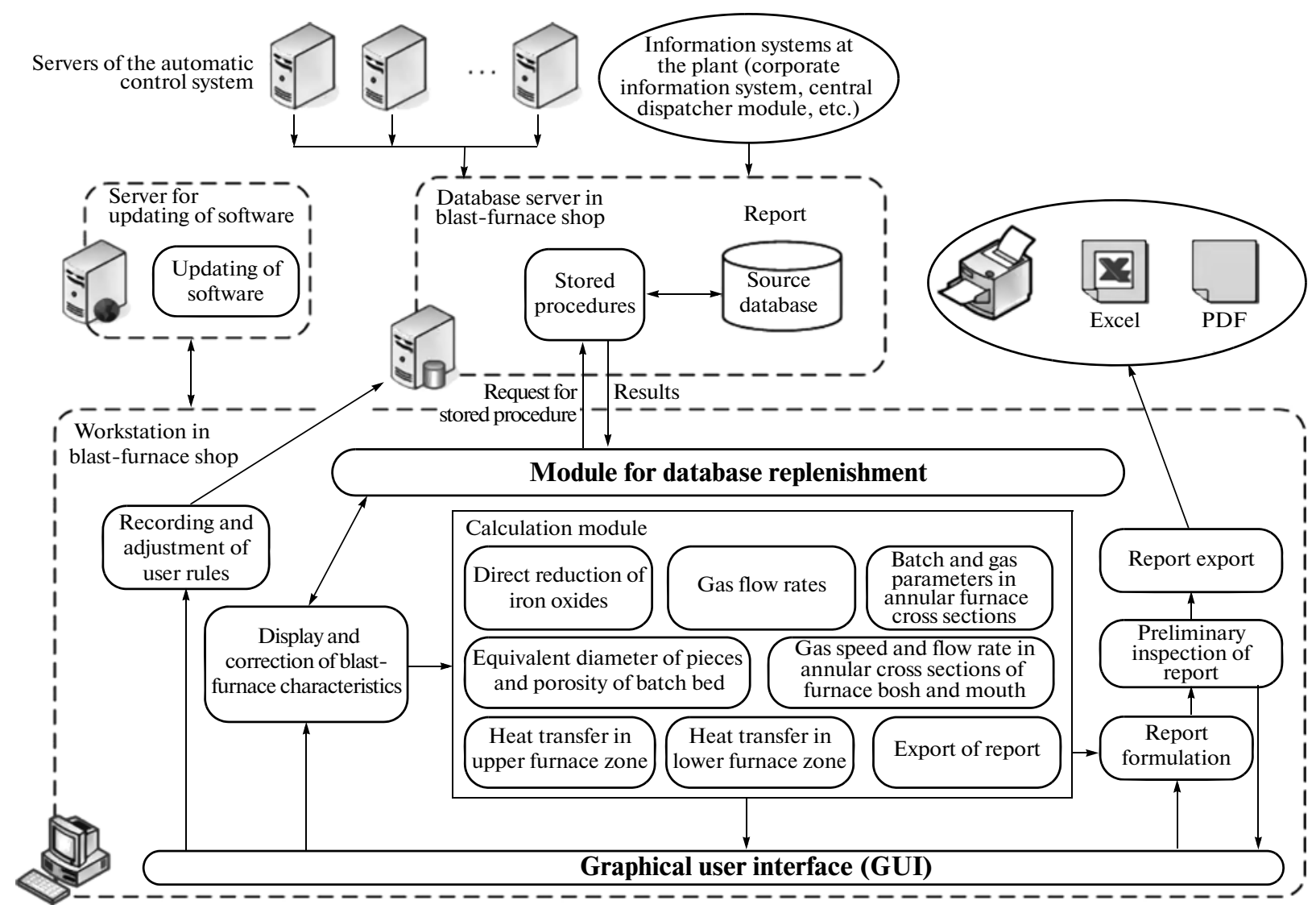

Fig. 2. Architecture of software.

fluxes, the ratio of the batch and gas fluxes, and the temperature distribution of the batch and gas in the upper and lower stages of heat transfer.

Module A7: determining the shape and size of the cohesion zones. This module calculates the geometric parameters and displays the viscoplastic zones in the iron ore within the blast furnace.

The creation of an automatic system for specifying the calculation modules is based on data flow diagrams (DFD) adapted for the display of mathematical formulas (calculation modules) [17]. The DFD approach calls for division of the mathematical model into individual functional components (processes), which are represented in the form of networks connected by data fluxes. The main goal here is to demonstrate how each process transforms the input data to output data and to reveal the relationship between these processes.

In Fig. 2, we show the architecture of the software for the information and simulation system, with its major components. The central element is the datastorage structure, which is formed on the database server of the information and computation center for blast-furnace production. The data are derived from the automatic control system in the blast-furnace shop, the corporate information system, and the central dispatcher module. Depending on the require- ments of the individual subsystems, different periods of data averaging are possible, by means of the database management system.

The architecture in Fig. 2 ensures the required functioning, satisfaction of the relevant requirements, relatively simple expansion and modification of the system, and autonomous implementation of individual program modules, regardless of the data-storage structure.

The software is modular. The basic client module is RingsFront, based on the executable file Rings.exe. The system employs Microsoft Visual Studio 2010 software and $\mathrm{C \#}$ programming language [16]. The main components of the computation module are dynamic-link libraries (dll):

-RingSolverLib.dll, a mathematical library for calculating the parameters of the heat-transfer processes in the upper and lower furnace zones and the shape and size of the viscoplastic iron-ore zones;

-ForecastLib.dll, a mathematical library for calculating the slag parameters in the blast furnace;

- Gazdin.dll, a mathematical library for calculating the gas-dynamic conditions in the furnace;

-BlastFurnaceGraphics.dll, a user component (control element) for visualization of the viscoplastic iron-ore zones in the blast furnace. 
(a)

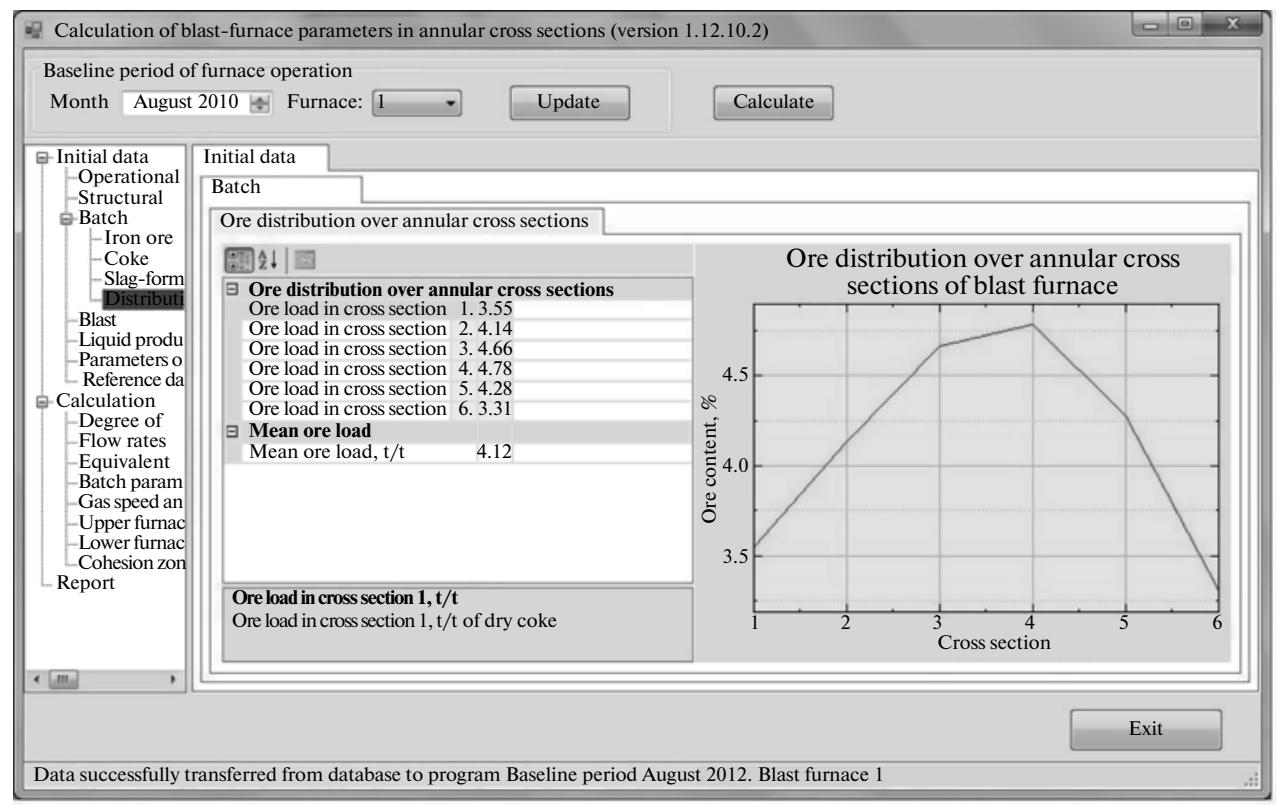

(b)

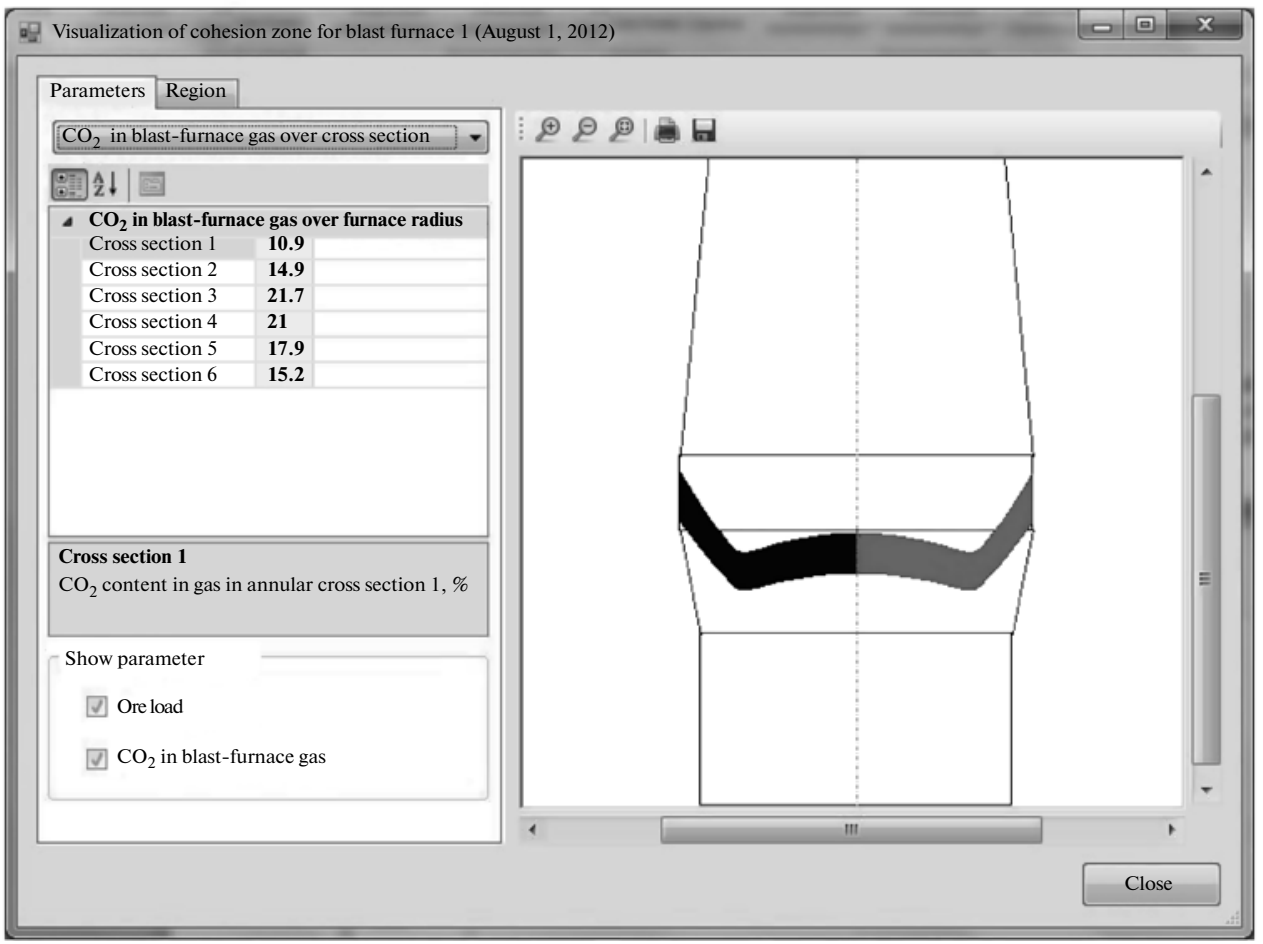

Fig. 3. Screen shots from the information and simulation system for the heat-transfer processes and cohesion zones in blast furnace 1 at OAO MMK: (a) primary window, with initial data; (b) visualization of cohesion zone.

The software for calculating the heat-transfer processes and parameters of the viscoplastic iron-ore zone in the blast furnace is part of the system for optimizing the blast-furnace process and for calculating and mapping the radial nonuniformity of the parameter distribution in the blast furnaces at OAO Magni- togorskii Metallurgicheskii Kombinat (MMK), on the basis of the following characteristics:

- characteristics of the direct reduction of iron ore;

- the gas flow rates;

- the batch and gas parameters over the annular cross sections; 
- the equivalent diameters of the coke pieces and the porosity of the batch bed;

- the gas speed and flow rate in annular cross sections of the furnace's bosh and mouth;

- the heat-transfer characteristics in upper and lower zones of the furnace;

- the shape and size of the viscoplastic iron-ore zones.

The software is intended for use by the engineering staff and forms part of the automated information system for the analysis and prediction of the blast-furnace processes at OAO MMK.

In Fig. 3, we present screen shots corresponding to the calculated ore distribution over the furnace radius and visualization of the shape and size of the cohesion zone according to production data for blast furnace 1 at OAO MMK.

\section{CONCLUSIONS}

The proposed information and simulation system, which is now in experimental operation at OAO MMK, allows the engineering staff to assess the position and shape of the viscoplastic iron-ore zone in the blast furnace on the basis of available operational information and also permits diagnostics of the zone's optimal configuration. In addition, the system proves useful as a predictive tool during the design period, with variation in the smelting parameters.

\section{REFERENCES}

1. Model'nye sistemy podderzhki prinyatiya reshenii $v$ ASU TP domennoi plavki metallurgii (Model Systems for the Support of Decision Making in Automatic Blast-Furnace Control), Spirin, N.A., Ed., Yekaterinburg: UrFU, 2011.

2. Komp'yuternye metody modelirovaniya domennogo protsessa (Computer Simulation of the Blast-Furnace Process), Spirin, N.A., Ed., Yekaterinburg: UGTU-UPI, 2005.
3. Yusfin, Yu.S., Metallurgiya chuguna (Metallurgy of Iron), Moscow: IKTs Akademkniga, 2004.

4. Blast Furnace Phenomena and Modelling, Omori, Y., Ed., New York: Elsevier, 1987.

5. Inada, S., Kabayasi, I., and Isabe, M., Tetsu to Kagane, 1984, vol. 43, no. 4, pp. 59-64.

6. Hatiga, S., Ono, R., Fuse, K., et al., Tetsu to Kagane, 1984, vol. 36, no. 3, pp. 77-80.

7. Vecehida, G. and Giuli, M., Rev. Metall.-CIT, 1984, vol. 781, no. 5, pp. 369-383.

8. Peters, K.H., Alpeter, W., Bachhofen, H.Y., et al., Stahl Eisen, 1984, vol. 104, no. 14, pp. 59-62.

9. Yamamoto, T., Shokyu, T., Kanoshima, H., et al., Trans. Iron Steel Inst. Japan, 1982, no. 10, p. 774.

10. Ohno, Y., Kondo, K., and Fukushima, T., Rev. Metall.CIT, 1983, no. 10 , pp. 809-825.

11. Kyle, I., Conference Proceedings, September 11-13, 1979, London, 1980, pp. 403-415.

12. Tovarovskii, I.G., Bol'shakov, V.I., and Merkulov, A.E., Analiticheskie issledovaniya domennoi plavki (Analysis of Blast-Furnace Processes), Dnepropetrovsk: ChMP Ekonomika, 2011.

13. Emel'yanov, S.V., Korovin, S.K., Myshlyaev, L.P., et al., Teoriya i praktika prognozirovaniya $v$ sistemakh upravleniya (Theory and Practice of Prediction in Control Systems), Kemerovo-Moscow: Izd. Ob'edinenie Rossiiskie Universitety, Kuzbassvuzizdat-ASTSh, 2008.

14. Odintsov, I.O., Professional'noe programmirovanie. Sistemnyi podkhod (Professional Programming: A Systems Approach), St. Petersburg: BKhV-Peterburg, 2004, 2nd ed.

15. Dubeikovskii, V.I., Effektivnoe modelirovanie $s$ CA ERwin Process Modeler (BPwin: AllFusionProcessModeler) (Effective Simulation with CA Erwin Process Modeler or BPwin AllFusionProcessModeler), Moscow: Dialog-MIFI, 2009.

16. Troelsen, A., Pro C\# 2010 and the .NET 4.0 Platform, Apress, 2011.

Translated by B. Gilbert 